\title{
Comparing the efficacy of endoscopic balloon dilation alone and combined with endoscopic sphincterotomy for common bile duct stone: a systematic review and meta-analysis
}

\author{
Jie $\mathrm{Hu}^{1}$, Ning $\mathrm{Mu}^{2}$, Yaxi $\mathrm{He}^{2}$ \\ ${ }^{1}$ Department of Radiology Oncology, Taizhou Central Hospital (Taizhou University Hospital), Taizhou, China; ${ }^{2}$ Department of General Surgery, \\ Taizhou First People's Hospital (Huangyan Hospital Affiliated to Wenzhou Medical University), Taizhou, China \\ Contributions: (I) Conception and design: J Hu; (II) Administrative support: Y He; (III) Provision of study materials or patients: N Mu; (IV) Collection \\ and assembly of data: J Hu; (V) Data analysis and interpretation: Y He; (VI) Manuscript writing: All authors; (VII) Final approval of manuscript: All \\ authors. \\ Correspondence to: Yaxi He. Department of General Surgery, Taizhou First People's Hospital (Huangyan Hospital Affiliated to Wenzhou Medical \\ University), Taizhou 318020, China. Email: heyx986824@163.com.
}

\begin{abstract}
Background Several comparative studies have shown that endoscopic balloon dilation (EPBD) combined with endoscopic sphincterotomy (EST) may be a better choice than EPBD alone for the treatment of common bile duct stones (CBDS). However, there are limited data that can be used to compare this combination method with EST or EPBD alone in the treatment of choledocholithiasis. Therefore, this study aimed to systematically evaluate the efficacy of EPBD alone and EPBD combined with EST in the treatment of CBDS.

Methods: We performed a literature search of the PubMed, Cochrane Central Register of Controlled Trials, Embase, Web of Science, China National Knowledge Infrastructure (CNKI), Wanfang, and Weipu databases using the following search terms: endoscopic balloon dilation, endoscopic sphincterotomy, sphincterotomy, balloon dilation, gallstones, bile duct stones, and common bile duct stones. The Cochrane risk of bias tool was used to evaluate the quality of the included studies, and the network meta-analysis was performed using RevMan 5.20.
\end{abstract}

Results: A total of nine articles satisfied the inclusion criteria, involving 497 patients who received EST + EPBD and 548 patients who underwent EPBD alone. The results of the meta-analysis showed that compared with the EPBD group, the EST + EPBD group had significant differences in the stone removal time [mean difference (MD) is $-1.83 ; 95 \%$ confidence interval $(\mathrm{CI}):(-3.57,-0.10)$ ] and the initial stone removal rate [relative risk (RR) is 1.11 ; $95 \% \mathrm{CI}:(1.04,1.19)$ ]. There were no significant differences in the rate of mechanical vibration stone crushing [RR is $0.74 ; 95 \% \mathrm{CI}:(0.55,1.00)]$, total rate of stone removal [RR is 1.01 ; $95 \%$ CI: $(0.98,1.04)]$, and complication rate [RR is $0.87 ; 95 \% \mathrm{CI}:(0.66,1.13)]$.

Discussion: The stone removal time and initial stone removal rate of patients in the EST + EPBD group were superior to those of patients in the EPBD group, and the two groups were similar in terms of total stone removal success rate, mechanical lithotripsy (ML) rate, and complication rate. Therefore, large-scale, multi-center prospective studies are needed to clarify whether EST + EPBD is superior to EPBD alone in the treatment of choledocholithiasis.

Keywords: Endoscopic balloon dilation (EPBD); endoscopic sphincterotomy (EST); bile duct stones; metaanalysis

Submitted Nov 12, 2021. Accepted for publication Jan 14, 2022.

doi: $10.21037 /$ apm-21-3557

View this article at: https://dx.doi.org/10.21037/apm-21-3557 


\section{Introduction}

Cholelithiasis is a common disease worldwide. The incidence of gallstones in adults ranges from $6-10 \%$ and increases with age, and the proportion of female patients may be twice that of male patients $(1,2)$. Common bile duct stones (CBDS) account for about $10-20 \%$ of patients with gallstones and are a common cause of abdominal pain. They can also be manifested as asymptomatic, bile stasis, as well as elevated liver enzymes and bilirubin. However, if it is not treated in time, CBDS can also develop into more serious conditions, such as bile duct obstruction, recurrent cholangitis, liver failure, pancreatitis, and even death. Early diagnosis and timely treatment are crucial to the treatment of choledocholithiasis $(1,3,4)$.

The European Society of Gastrointestinal Endoscopy (ESGE) recommends liver function tests and abdominal ultrasound as a preliminary screening method for choledocholithiasis. Patients with suspected choledocholithiasis but lacking evidence should be further subjected to endoscopic retrograde cholangiopancreatography (ERCP) or magnetic resonance cholangiopancreatography (MRCP) to confirm the diagnosis (5). MRCP can diagnose CBDS to a certain extent, because it can identify $91 \%$ of bile duct stones, but stones smaller than $5 \mathrm{~mm}$ can only be detected in $71 \%$ of patients. A recent meta-analysis showed that compared with MRCP, ERCP has higher sensitivity, specificity, and accuracy in the diagnosis of choledocholithiasis. However, ERCP can lead to post-ERCP pancreatitis (PEP), bile duct inflammation, retroperitoneal perforation, bleeding after sphincterotomy, and anesthesia-related complications; therefore, the clinical application of ERCP is limited (1).

The ESGE suggests that patients with CBDS, whether symptomatic or asymptomatic, should be treated with stone removal if the patient's physical condition is sufficient to withstand the operation (5). Currently, CBDS treatment methods include endoscopic surgery, laparoscopic or open common bile duct exploration, and extracorporeal shockwave lithotripsy (ESWL), among others. As an effective, safe, and extremely low-mortality surgical method, endoscopy is the most widely applied and has gradually become the primary treatment method for CBDS. Endoscopic balloon dilation (EPBD) is considered as an alternative treatment method for endoscopic sphincterotomy (EST), which is easier to perform than EST, and because it retains the structural integrity of the Oddi sphincter (SOD), and it can reduce the incidence of bleeding, perforation, and other complications (6).
However, compared with EST, EPBD also has some limitations. For example, it is difficult to remove large stones due to the small bile duct opening, mechanical lithotripsy (ML) is required more frequently, and the incidence of pancreatitis after surgery is higher (7). Recent studies have found that the combination of EST and EPBD is relatively safe, and proper sphincterotomy can effectively guide the expansion toward the bile duct sphincter instead of the pancreatic duct sphincter, thereby reducing the risk of postoperative pancreatitis $(8,9)$.

However, there is no systematic evaluation of the efficacy of EPBD alone and combined with EST in the treatment of choledocholithiasis. Therefore, this study evaluated the efficacy and safety of EPBD alone and combined with EST in the treatment of choledocholithiasis by including existing randomized controlled trials (RCTs). We present the following article in accordance with the PRISMA reporting checklist (available at https://apm.amegroups.com/article/ view/10.21037/apm-21-3557/rc).

\section{Methods}

\section{Search strategy}

We performed a literature search of English biomedical databases, including PubMed, Cochrane Central Register of Controlled Trials, Embase, and Web of Science, and major Chinese biomedical databases, including China National Knowledge Infrastructure (CNKI), Wanfang, and Weipu. The remaining records are obtained from websites, organizations and citation searching. The search period is from the date of establishment of the database to August 30, 2021. The following search terms were used as keywords: endoscopic balloon dilation, endoscopic sphincterotomy, sphincterotomy, balloon dilation, gallstones, bile duct stones, and common bile duct stones. We conducted a comprehensive search based on the search characteristics of each database.

\section{Inclusion criteria}

The inclusion criteria were as follows: (I) RCTs comparing EPBD and EST + EPBD in the treatment of choledocholithiasis; (II) patients aged $\geq 18$ years, without restriction on the gender or disease course; (III) choledocholithiasis diagnosis confirmed by ERCP and/or imaging; (IV) studies where the control group was EPBD alone, and the observation group was EST + EPBD; (V) 
both groups could receive other basic treatments, but should be the same; and (VI) outcome indicators including any of the following: stone removal time, initial stone removal success rate, ML rate, total stone removal success rate, and the incidence of complications.

\section{Exclusion criteria}

The exclusion criteria were as follows: (I) studies involving patients accompanied by acute pancreatitis; (II) studies involving patients with suspected or confirmed malignant tumors of the biliary tract, ampulla, and pancreas; (III) studies involving patients with coagulation dysfunction or diseases with bleeding tendency; (IV) articles involving patients with severe cardiopulmonary insufficiency and severe liver and kidney disease; (V) studies involving patients that could not tolerate endoscopic treatment; and (VI) studies involving patients with a history of EPBD and EST surgery.

\section{Paper screening and risk of bias}

Two reviewers independently evaluated the titles and abstracts of the same articles to determine whether they fit the research scope. If both reviewers believed that an article met the requirements of the research, the full text was reviewed; otherwise, it was excluded. Any disagreements between the reviewers about whether an article could be included in this research were resolved through discussion or judgment by a third reviewer.

The Cochrane risk of bias tool was used to assess the quality and risk of bias of the included articles based on the following evaluation items: random sequence generation, allocation concealment, blinding of investigators and subjects, blinded evaluation of research outcomes, completeness of outcome data, selective outcome reports, and other biases. According to this evaluation, the biases were classified into high-risk, low-risk, and unclear. The two reviewers performed the above process separately, and any differences were resolved by discussion.

\section{Data extraction}

Patients involved in the included articles were divided into two groups: an EST + EPBD group and an EPBD group. The two reviewers also independently extracted the data in accordance with the pre-established data tables, including the author's name, country, publication time, journal name, and patient demographics. The recorded results included the stone removal time, initial stone removal success rate, ML rate, total stone removal success rate, and the incidence of complications.

\section{Statistical analysis}

Percentages and relative risk (RR) or mean difference (MD) with $95 \%$ confidence interval (CI) were used to describe the data. The heterogeneity of indicators between studies were evaluated based on the $\mathrm{I}^{2}$ test. If the heterogeneity between studies was small $\left(\mathrm{P}>0.1 ; \mathrm{I}^{2}<50 \%\right)$, the fixed effects model was used to merge the effect sizes; however, if the heterogeneity between studies was obvious ( $\left.\mathrm{P} \leq 0.1 ; \mathrm{I}^{2} \geq 50 \%\right)$, the random effects model was used to merge the effect size. And a sensitivity analysis was carried out according to the Cochrane systematic review method. Statistical analysis and graphs were performed using RevMan 5.20 software provided by the Cochrane Collaboration. $\mathrm{P} \leq 0.05$ was considered to indicate a statistically significant difference, and the funnel plot was used to assess the risk of publication bias.

\section{Results}

\section{Search results and study characteristics}

There were 1,023 records confirmed from the database literature search. Of these, 885 documents were obtained by literature screening ( 41 duplicate records were removed and 97 records were marked as ineligible by automation tools). After excluding 128 low quality records, 757 documents remained. Of these, 674 articles were obtained after literature retrieval. We then read the full texts of the remaining articles based on the inclusion and exclusion criteria, and excluded articles with incomplete data (those with no research indicators), non-RCTs, and those that did not meet the criteria. Finally, nine articles that could be used for meta-analysis were obtained after screened. The records obtained from websites, organizations and citation searching are all excluded after screening. The specific process is shown in Figure 1.

Among the nine included articles, four articles reported the stone removal time, seven articles reported the initial stone removal success rate, all nine articles reported the mechanical stone fragmentation rate, eight articles reported the total rate of stone removal, and all nine articles reported the incidence of complications. All selected articles included 


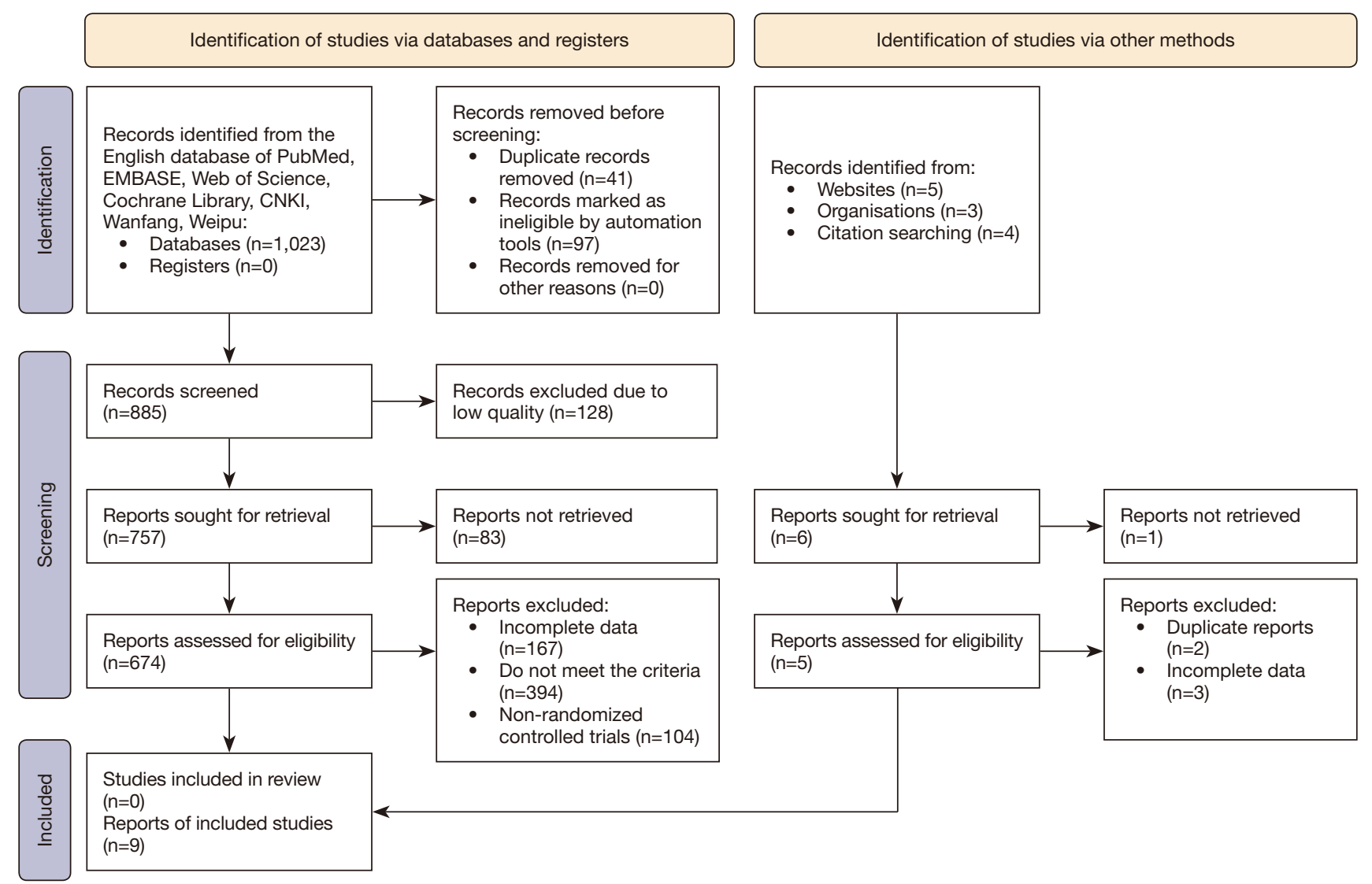

Figure 1 Flow diagram of the search, screening, and inclusion process. CNKI, China National Knowledge Infrastructure.

a clear diagnosis as well as inclusion and exclusion criteria. In total, 497 patients received EST + EPBD and 548 patients underwent EPBD. The basic characteristics of the article are shown in Table 1.

Three articles (3/9) described random sequence generation, four articles (4/9) reported allocation concealment, one article (1/9) described the use of the double-blind method. None of the included articles described the blinded evaluation of outcome assessment, and all articles described the complete outcome data, selective reporting, and other biases. The assessment results are shown in Figure 2.

\section{Meta-analysis results}

\section{Stone removal time}

According to the inclusion and exclusion criteria, four articles were included to analyze the difference in stone removal time between EST + EPBD and EPBD treatment of CBDS, with a total of 274 EST + EPBD-treated patients and $277 \mathrm{EPBD}$-treated patients. The analysis results $\left(\mathrm{P}=0.16 ; \mathrm{I}^{2}=42 \%\right)$ indicated that there was no heterogeneity between the stone removal time between the two groups of patients, so the fixed effects model was used for combined analysis. The combined effect size MD was $-1.83,95 \% \mathrm{CI}$ : $(-3.57,-0.10)$, as shown in Figure 3. The comprehensive effect size test result was $\mathrm{Z}=2.07, \mathrm{P}=0.04$, and thus, the meta-analysis results indicated that the stone removal rate of the EST + EPBD treatment group was statistically different compared with the EPBD treatment group alone.

\section{Initial stone removal rate}

According to the inclusion and exclusion criteria, a total of seven articles were included to analyze the difference in the initial stone removal rate between EST + EPBD and EPBD treatment of CBDS, with a total of 351 EST + EPBD-treated patients and 415 EPBD-treated patients. The analysis results $\left(\mathrm{P}=0.19 ; \mathrm{I}^{2}=31 \%\right)$ indicated that there 
Table 1 Basic characteristics of the included articles

\begin{tabular}{|c|c|c|c|c|c|}
\hline Author & Country/region & Year & Journal & EST + EPBD group $(n)$ & EPBD group $(n)$ \\
\hline Chu et al. (11) & China & 2017 & European Surgery & 33 & 30 \\
\hline Guo et al. (12) & China & 2015 & Med Sci Monit & 85 & 85 \\
\hline Kuo et al. (8) & Taiwan & 2019 & BMC Gastroenterol & 58 & 96 \\
\hline Okuno et al. (2) & Japan & 2016 & Dig Dis Sci & 27 & 55 \\
\hline Park et al. (9) & South Korea & 2019 & Endoscopy & 100 & 100 \\
\hline Tao et al. (14) & China & 2017 & China Journal of Endoscopy & 38 & 40 \\
\hline Wang et al. (15) & China & 2015 & Chin J Dig Endosc & 51 & 52 \\
\hline
\end{tabular}

EST, endoscopic sphincterotomy; EPBD, endoscopic balloon dilation.

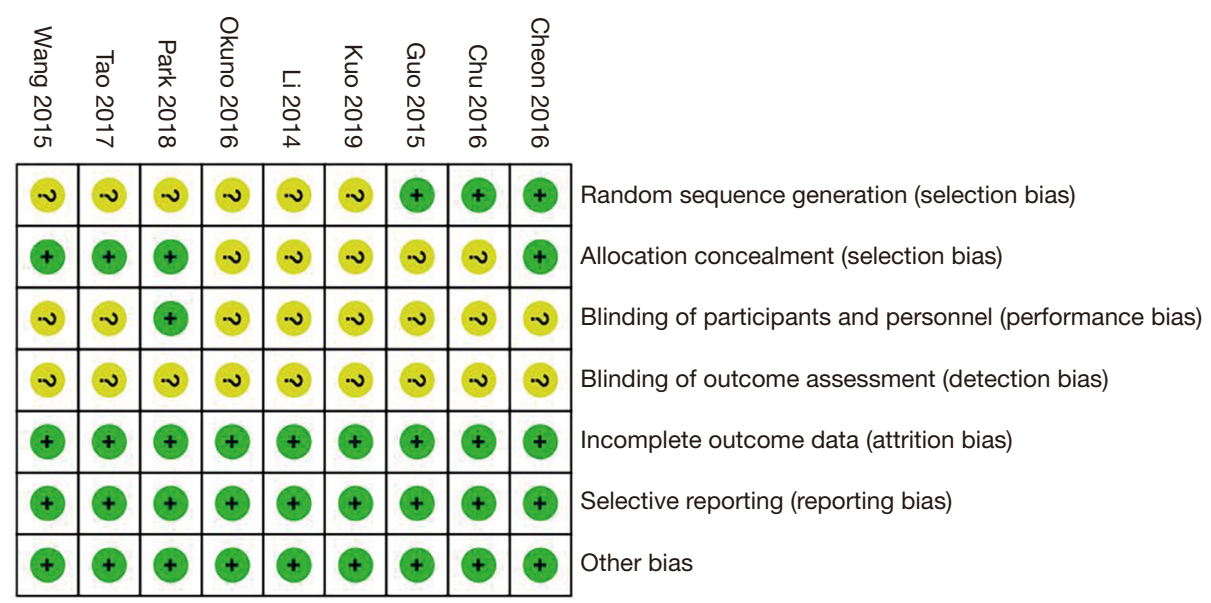

Figure 2 Literature quality evaluation details.

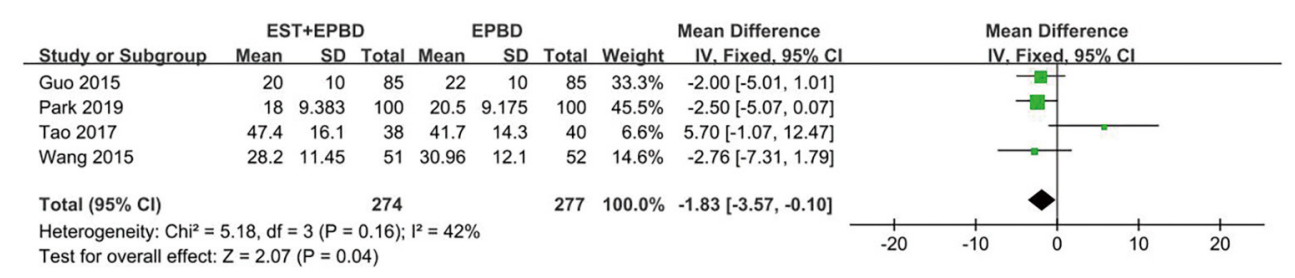

Figure 3 Forest plot of stone removal time. Comparison of stone removal time between the EST + EPBD group and the EPBD group. Statistical method: inverse variance of fixed effects model (MD and 95\% CI). EST, endoscopic sphincterotomy; EPBD, endoscopic balloon dilation; MD, mean difference; CI, confidence interval.

was no heterogeneity in the stone removal time between the two groups of patients, so the fixed effects model was used for combination analysis. The combined effect size RR was $1.11,95 \%$ CI: $(1.04,1.19)$, as shown in Figure 4. The comprehensive effect size test result was $Z=3.29, P=0.0010$, and therefore, the meta-analysis results suggest that the initial stone removal rate in the EST + EPBD and EPBS treatment groups were significantly different. 


\begin{tabular}{|c|c|c|c|c|c|c|c|c|c|c|}
\hline \multirow{2}{*}{$\begin{array}{l}\text { Study or Subgroup } \\
\text { Cheon } 2016\end{array}$} & \multicolumn{2}{|c|}{ EST+EPBD } & \multicolumn{2}{|c|}{ EPBD } & Weight & $\begin{array}{l}\text { Risk Ratio } \\
\mathrm{M}-\mathrm{H} \text {. Fixed, } 95 \% \mathrm{Cl}\end{array}$ & \multicolumn{3}{|c|}{$\begin{array}{c}\text { Risk Ratio } \\
\mathrm{M}-\mathrm{H} \text {. Fixed. } 95 \% \mathrm{Cl}\end{array}$} & \\
\hline & 43 & 44 & 40 & 42 & $14.0 \%$ & $1.03[0.95,1.11]$ & & & $T$ & \\
\hline Chu 2016 & 26 & 33 & 20 & 30 & $7.2 \%$ & $1.18[0.87,1.61]$ & & & & \\
\hline Kuo 2019 & 57 & 58 & 83 & 96 & $21.4 \%$ & $1.14[1.04,1.24]$ & & & $\rightarrow$ & \\
\hline Okuno 2016 & 22 & 27 & 37 & 55 & $8.3 \%$ & $1.21[0.94,1.57]$ & & & & \\
\hline Park 2019 & 78 & 100 & 77 & 100 & $26.3 \%$ & $1.01[0.87,1.18]$ & & & & \\
\hline Tao 2017 & 31 & 38 & 30 & 40 & $10.0 \%$ & $1.09[0.86,1.37]$ & & & 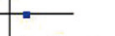 & \\
\hline Wang 2015 & 48 & 51 & 38 & 52 & $12.9 \%$ & $1.29[1.08,1.54]$ & & & & \\
\hline Total $(95 \% \mathrm{Cl})$ & & 351 & & 415 & $100.0 \%$ & $1.11[1.04,1.19]$ & & & 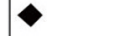 & \\
\hline Total events & 305 & & 325 & & & & & & & \\
\hline $\begin{array}{l}\text { Heterogeneity: } \mathrm{Chi}^{2}= \\
\text { Test for overall effect }\end{array}$ & $\begin{array}{l}74, d f=6 \\
=3.29(P\end{array}$ & $\begin{array}{l}(P=0 . \\
=0.00\end{array}$ & $\begin{array}{l}\text { 19); } 1^{2}=3 \\
10)\end{array}$ & $31 \%$ & & & 0.5 & 0.7 & 1.5 & 2 \\
\hline
\end{tabular}

Figure 4 Forest plot of initial stone removal rate. Comparison of initial stone removal rate between the EST + EPBD group and the EPBD group. Statistical method: Mantel-Haenszel of the fixed effects model (RR and 95\% CI). EST, endoscopic sphincterotomy; EPBD, endoscopic balloon dilation; RR, relative risk; CI, confidence interval.

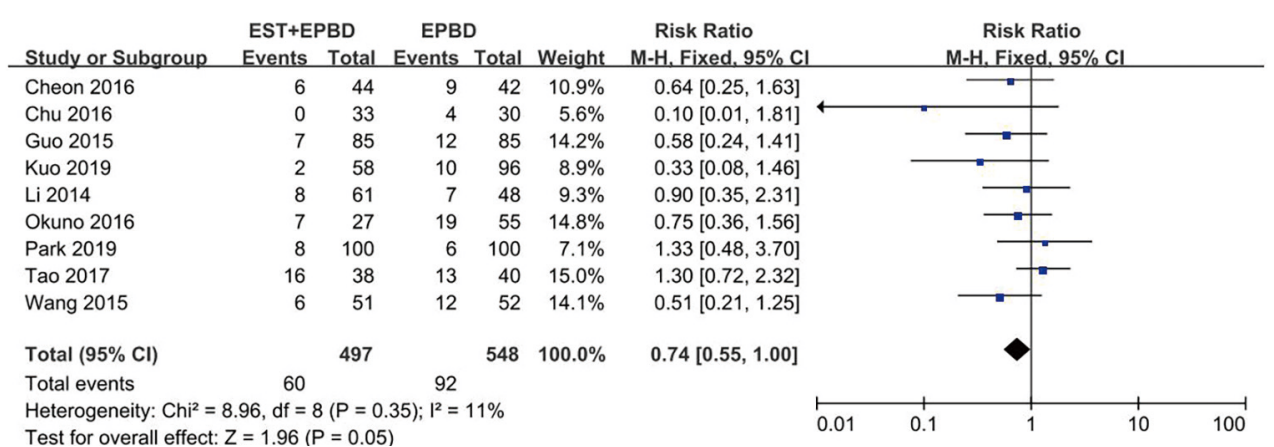

Figure 5 Forest plot of mechanical stone fragmentation rate. Comparison of mechanical stone fragmentation rate between the EST + EPBD group and the EPBD group. Statistical method: Mantel-Haenszel of the fixed effects model (RR and 95\% CI). EST, endoscopic sphincterotomy; EPBD, endoscopic balloon dilation; RR, relative risk; CI, confidence interval.

\section{Mechanical stone fragmentation rate}

A total of nine articles were included to analyze the difference in the rate of mechanical crushing stones between $\mathrm{EST}+\mathrm{EPBD}$ and EPBD alone in the treatment of CBDS, with a total of 497 EST + EPBD-treated patients and 548 EPBD-treated patients. The analysis results $(\mathrm{P}=0.35$; $\mathrm{I}^{2}=11 \%$ ) indicated that there was no heterogeneity between the two groups of patients in using mechanical vibration to break the stones, so the fixed effects model was used for combined analysis. The combined effect size RR was 0.74, 95\% CI: $(0.55,1.00)$, as shown in Figure 5. The result of the comprehensive effect size test was $\mathrm{Z}=1.96, \mathrm{P}=0.05$. Therefore, the meta-analysis results suggest that the rate of stone fragmentation using mechanical vibration in the EST + EPBD treatment group was not significantly different to that of the EPBD treatment group.

\section{Total rate of stone removal}

A total of eight articles were included to analyze the difference in total stone removal rate between EST + EPBD and EPBD treatment of CBDS, with a total of 459 EST + EPBD-treated patients and 508 EPBD-treated patients. The analysis results $\left(\mathrm{P}=0.61 ; \mathrm{I}^{2}=0 \%\right)$ indicated that there was no heterogeneity in the total stone removal rate between the two groups of patients, so the fixed effects model was used for combined analysis. The combined effect size RR was $1.01,95 \%$ CI: $(0.98,1.04)$, as shown in Figure 6 . The comprehensive effect size test result was $\mathrm{Z}=0.66, \mathrm{P}=0.51$, and thus, the meta-analysis results indicate that the total stone removal rate was not significantly different between the EST + EPBD and EPBD treatment groups.

\section{Complication rate}

A total of nine articles were included to analyze the difference in complication rates between EST + EPBD and EPBD treatment of CBDS, with a total of 497 EST + EPBD-treated patients and 548 EPBD-treated patients. The analysis results $\left(\mathrm{P}=0.89 ; \mathrm{I}^{2}=0 \%\right)$ indicated that there was no heterogeneity in the incidence of complications between the two groups of patients, so the fixed effects 


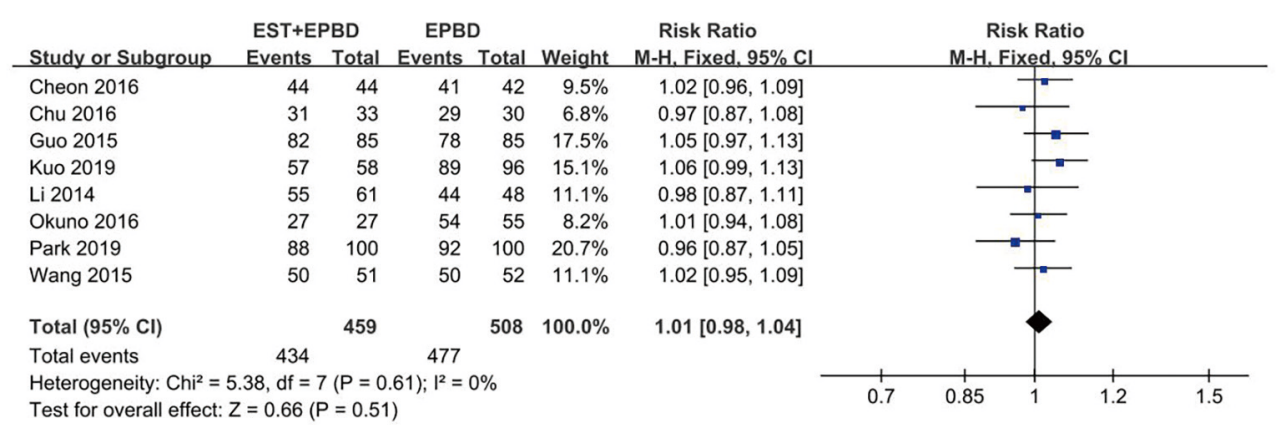

Figure 6 Forest plot of total rate of stone removal. Comparison of total rate of stone removal between the EST + EPBD group and the EPBD group. Statistical method: Mantel-Haenszel of the fixed effects model (RR and 95\% CI). EST, endoscopic sphincterotomy; EPBD, endoscopic balloon dilation; RR, relative risk; CI, confidence interval.

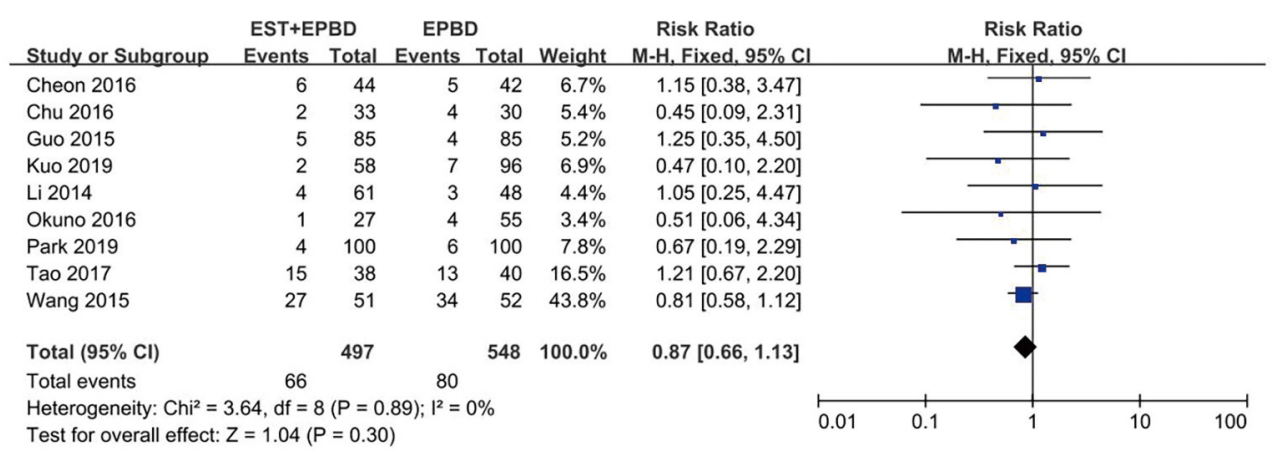

Figure 7 Forest plot of complication rate. Comparison of complication rate between the EST + EPBD group and the EPBD group. Statistical method: Mantel-Haenszel of the fixed effects model (RR and 95\% CI). EST, endoscopic sphincterotomy; EPBD, endoscopic balloon dilation; RR, relative risk; CI, confidence interval.

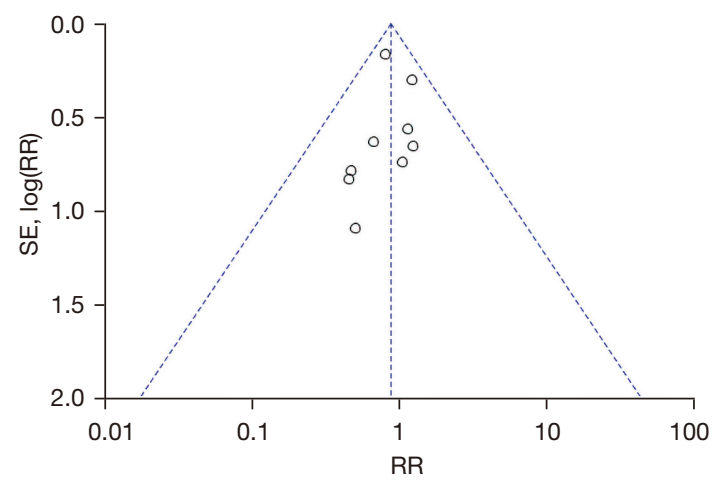

Figure 8 Funnel plot analysis of possible publication bias in the subgroup of complication rate. SE, standard error of the mean; $\mathrm{RR}$, relative risk.

model was used for combined analysis. The combined effect size RR was $0.87,95 \%$ CI: $(0.66,1.13)$, as shown in Figure 7. The result of the comprehensive effect size test was $\mathrm{Z}=1.04$,
$\mathrm{P}=0.30$. Thus, the meta-analysis results indicate that the incidence of complications was not significantly different between the EST + EPBD and EPBD treatment groups.

\section{Publication bias}

A funnel plot was used to examine the publication bias of the complication rate. As shown in Figure 8, it can be seen that the funnel plot showed symmetry, indicating that there was no publication bias.

\section{Risk of bias}

Among the included studies, three articles had a low risk of random sequence generation bias (10-12), while the remaining six articles had an unclear risk (2,8,9,13-15). Four articles had a low risk of hidden allocation bias $(9,10,14,15)$, while the remaining five articles had an unclear risk (2,8,11-13). One article had a low risk of blinding bias between subjects and researchers (9), while the remaining eight articles had an unclear risk $(2,8,10-15)$. All articles had an unclear risk of 


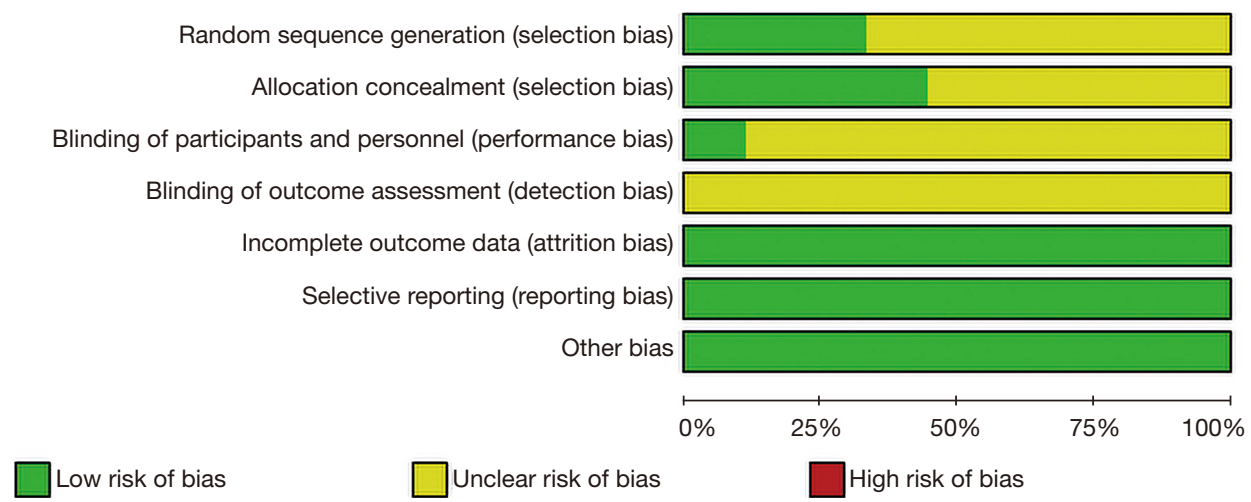

Figure 9 The intensity and distribution of the quality risk of the articles included in the study.

blinding method bias, while the risks of complete result data bias, selective reporting domain bias, and other bias of all articles was low (as shown in Figure 9).

\section{Discussion}

At present, endoscopic treatment has become the preferred treatment for choledocholithiasis $(9,12)$, and EST is currently recognized as the standard treatment for choledocholithiasis (16). Compared with other operations, EST has the advantages of being minimally invasive and having a short operation time; however, the risks of perforation, bleeding, and acute pancreatitis are higher. In order to reduce these risks, surgeons have achieved good results with EPBD instead of EST (7). However, EPBD alone cannot completely remove larger stones. It is speculated that the combination of EST and EPBD in the treatment of CBDS (17) can reduce edema after duodenal papilla dilation, thereby preventing PEP (18). However, the results of several studies are not consistent $(8,19)$. Therefore, a summary of the different comparative studies between EPBD and EST + EPBD is necessary.

The results of this study show that there is no difference between EST + EPBD and EPBD, regardless of the success rate of stone removal or the rate of $M L$, indicating that EPBD alone is sufficient to fully expand the nipple to remove stones, and the combination with EST is not a reasonable way to improve the curative effect. Moreover, there is no difference in the complication rate between EST + EPBD and EPBD, suggesting that the safety of the two is similar, which is consistent with the findings of Okuno et al. $(2,8,13)$, although the specific reasons require further research. However, the stone removal time and initial stone removal rate of EST + EPBD is better than that of EPBD alone. Using EST + EPBD to treat CBDS with the same basic treatment may reduce the patient's operation time and increase the probability of initial stone removal.

It can be seen from the existing literature that although the degree of papillary muscle incision is different, as long as the large-size expansion balloon is combined, the success rate of stone removal will be improved $(8,20,21)$, which suggests that the CBDS patients who do not need to cut the papillary sphincter before large-diameter balloon dilation may achieve the same effect (22), although further research is needed to confirm this. Finally, it can be seen from this meta-analysis that the EST + EPBD group has a relatively shorter operation time $(23,24)$. In theory, since EPBD alone is easier to perform than EST + EPBD, the reason for shortening the operation time is that EST increases the progress of the operation, which also increases the probability of initial stone removal. It may also be due to the combination of the two surgical methods, which reduces the number of times to remove stones, thereby shortening the operation time.

However, this study has some limitations that should be noted. Firstly, although a large number of English and Chinese databases were searched, most of the included studies were from China, and thus, the patients were mostly Chinese, which may have led to some publication bias. Secondly, some RCTs did not describe the specific random sequence generation method. Thirdly, the current research sample size is small and lacks representativeness. Therefore, further multi-center large sample studies are needed to determine the efficacy of EST + EPBD compared with EPBD in patients with choledocholithiasis. Despite the limitations, this study systematically evaluated the effectiveness and safety of EPBD and EST + EPBD in the treatment of choledocholithiasis. 


\section{Conclusions}

In this study, we found that both the EST + EPBD treatment group and the EPBD treatment alone group were similar in terms of the total stone removal success rate, ML rate, and complication rate. However, the stone removal time and initial stone removal rate of the EST + EPBD group were superior to those of the EPBD group. Given the advantages of EST + EPBD, large-scale, multi-center prospective research is needed to verify whether EST + EPBD can replace EPBD.

\section{Acknowledgments}

Funding: None.

\section{Footnote}

Reporting Checklist: The authors have completed the PRISMA reporting checklist. Available at https://apm. amegroups.com/article/view/10.21037/apm-21-3557/rc

Conflicts of Interest: All authors have completed the ICMJE uniform disclosure form (available at https://apm. amegroups.com/article/view/10.21037/apm-21-3557/coif). The authors have no conflicts of interest to declare.

Ethical Statement: The authors are accountable for all aspects of the work in ensuring that questions related to the accuracy or integrity of any part of the work are appropriately investigated and resolved.

Open Access Statement: This is an Open Access article distributed in accordance with the Creative Commons Attribution-NonCommercial-NoDerivs 4.0 International License (CC BY-NC-ND 4.0), which permits the noncommercial replication and distribution of the article with the strict proviso that no changes or edits are made and the original work is properly cited (including links to both the formal publication through the relevant DOI and the license). See: https://creativecommons.org/licenses/by-nc-nd/4.0/.

\section{References}

1. Khoury T, Adileh M, Imam A, et al. Parameters Suggesting Spontaneous Passage of Stones from Common Bile Duct: A Retrospective Study. Can J Gastroenterol Hepatol 2019;2019:5382708.
2. Okuno M, Iwashita T, Yoshida K, et al. Significance of Endoscopic Sphincterotomy Preceding Endoscopic Papillary Large Balloon Dilation in the Management of Bile Duct Stones. Dig Dis Sci 2016;61:597-602.

3. Park CH. The Management of Common Bile Duct Stones. Korean J Gastroenterol 2018;71:260-3.

4. Wilkins T, Agabin E, Varghese J, et al. Gallbladder Dysfunction: Cholecystitis, Choledocholithiasis, Cholangitis, and Biliary Dyskinesia. Prim Care 2017;44:575-97.

5. Manes G, Paspatis G, Aabakken L, et al. Endoscopic management of common bile duct stones: European Society of Gastrointestinal Endoscopy (ESGE) guideline. Endoscopy 2019;51:472-91.

6. Haseeb A, Freeman ML. Endoscopic Papillary Large Balloon Dilation Versus Endoscopic Sphincterotomy for Treatment of Bile Duct Stones. Curr Treat Options Gastroenterol 2019;17:221-30.

7. Aiura K, Kitagawa Y. Current status of endoscopic papillary balloon dilation for the treatment of bile duct stones. J Hepatobiliary Pancreat Sci 2011;18:339-45.

8. Kuo CM, Chiu YC, Liang CM, et al. The efficacy of limited endoscopic sphincterotomy plus endoscopic papillary large balloon dilation for removal of large bile duct stones. BMC Gastroenterol 2019;19:93.

9. Park JS, Jeong S, Lee DK, et al. Comparison of endoscopic papillary large balloon dilation with or without endoscopic sphincterotomy for the treatment of large bile duct stones. Endoscopy 2019;51:125-32.

10. Cheon YK, Lee TY, Kim SN, et al. Impact of endoscopic papillary large-balloon dilation on sphincter of Oddi function: a prospective randomized study. Gastrointest Endosc 2017;85:782-90.e1.

11. Chu X, Zhang H, Qu R, et al. Small endoscopic sphincterotomy combined with endoscopic papillary largeballoon dilation in the treatment of patients with large bile duct stones. European Surgery 2017;49:9-16.

12. Guo Y, Lei S, Gong W, et al. A Preliminary Comparison of Endoscopic Sphincterotomy, Endoscopic Papillary Large Balloon Dilation, and Combination of the Two in Endoscopic Choledocholithiasis Treatment. Med Sci Monit 2015;21:2607-12.

13. Li QL, Gao WD, Zhang C, et al. Is endoscopic sphincterotomy plus large-balloon dilation a better option than endoscopic large-balloon dilation alone in removal of large bile duct stones? A retrospective comparison study. Indian J Cancer 2015;51 Suppl 2:e13-7.

14. Tao L, Yaping X U, Yao J. Comparison of EPBD and 
EPBD combined with SEST in treatment of large choledocholithiasis. China Journal of Endoscopy 2017;23:82-6.

15. Wang Y, Ye L, Lin M, et al. A comparative study on three endoscopic methods for removal of common bile duct stones accompa-nied with periampullary diverticula. Chin J Dig Endosc 2015;32:290-5.

16. Williams E, Beckingham I, El Sayed G, et al. Updated guideline on the management of common bile duct stones (CBDS). Gut 2017;66:765-82.

17. Ersoz G, Tekesin O, Ozutemiz AO, et al. Biliary sphincterotomy plus dilation with a large balloon for bile duct stones that are difficult to extract. Gastrointest Endosc 2003;57:156-9.

18. Shim CS, Kim JW, Lee TY, et al. Is endoscopic papillary large balloon dilation safe for treating large CBD stones? Saudi J Gastroenterol 2016;22:251-9.

19. Liu P, Lin H, Chen Y, et al. Comparison of endoscopic papillary large balloon dilation with and without a prior endoscopic sphincterotomy for the treatment of patients with large and/or multiple common bile duct stones: a systematic review and meta-analysis. Ther Clin Risk Manag 2019;15:91-101.

20. Aujla UI, Ladep N, Dwyer L, et al. Endoscopic papillary

Cite this article as: $\mathrm{Hu} \mathrm{J}, \mathrm{Mu} \mathrm{N}, \mathrm{He}$ Y. Comparing the efficacy of endoscopic balloon dilation alone and combined with endoscopic sphincterotomy for common bile duct stone: a systematic review and meta-analysis. Ann Palliat Med 2022;11(1):163-172. doi: 10.21037/apm-21-3557 large balloon dilation with sphincterotomy is safe and effective for biliary stone removal independent of timing and size of sphincterotomy. World J Gastroenterol 2017;23:8597-604.

21. Hakuta R, Kawahata S, Kogure H, et al. Endoscopic papillary large balloon dilation and endoscopic papillary balloon dilation both without sphincterotomy for removal of large bile duct stones: A propensity-matched analysis. Dig Endosc 2019;31:59-68.

22. Omuta S, Maetani I, Saito M, et al. Is endoscopic papillary large balloon dilation without endoscopic sphincterotomy effective? World J Gastroenterol 2015;21:7289-96.

23. Itoi T, Itokawa F, Sofuni A, et al. Endoscopic sphincterotomy combined with large balloon dilation can reduce the procedure time and fluoroscopy time for removal of large bile duct stones. Am J Gastroenterol 2009;104:560-5.

24. Tsuchida K, Iwasaki M, Tsubouchi M, et al. Comparison of the usefulness of endoscopic papillary large-balloon dilation with endoscopic sphincterotomy for large and multiple common bile duct stones. BMC Gastroenterol 2015;15:59.

(English Language Editor: A. Kassem) 